\title{
MEMANFAATKAN KEARIFAN LOKAL UNTUK MENGEMBANGKAN KREATIVITAS SISWA PADA PELAJARAN SOSIOLOGI SMA NEGERI 6 YOGYAKARTA
}

\author{
RIRIN WAHYU PRIYANTI
}

\begin{abstract}
Abstrak
Peneliti tertarik pada strategi pembelajaran yang kreatif, maka muncullah ide untuk menerapkannya dalam proses pembelajaran di dalam kelas. Sehingga dimanfaatkan kearifan local untuk mengembangkan kreativitas siswa dalam materi pelajaran "modernisasi dan globalisasi".

Penelitian ini termasuk jenis class action research. Rumusan masalahnya adalah; 1) apakah kreativitas siswa dapat meningkat dengan diterapkan metode memanfaatkan kearifan local, 2) bagaimana sisa dapat lebih mengenal budaya lokal dan melestarikannya, 3) apakah prestasi siswa dapat lebih meningkat dengan diterapkannya metode pembelajaran yang berbeda pada setiap siklus. Tujuannya untuk meningkatkan kreativitas siswa, mengenalkan langsung pada aset budaya lokal dan meningkatkan prestasi siswa.

Pada siklus pertama, siswa diberikan kesempatan untuk diskusi kelompok di dalam kelas, siklus kedua siswa diberikan metode studi library dan meresume hasilnya dalam bentuk artikel, siklus ketiga siswa ditugaskan mengunjungi sekaligus meneliti eksistensi asset budaya lokal. Kesimpulan dalam penelitian ini; 1) kreativitas siswa meningkat, 2) siswa lebih mengenal dari dekat dan dapat belajar langsung pada aspek budaya lokal, 3) prestasi siswa meningkat dari siklus ke siklus, siklus pertama $60 \%$ siswa aktif, siklus kedua $75 \%$ dan siklus ketiga $100 \%$. Saran yang dapat diberikan; perlu disusun model dan proses pembelajaran yang dapat mengembangkan kreativitas, penyusunan bahan ajar disesuaikan dengan potensi dan karakteristik daerah, perubahan metode pembelajaran sosiologi sebagai ilmu sosial harus dilakukan dengan memanfaatkan kearifan lokal sebagai sumber belajar.

Kata Kunci: kearifan lokal, kreativitas, strategi pembelajaran, sosialisasi, "modernisasi \&globalisasi"
\end{abstract}




\title{
UTILIZING LOCAL WISDOM FOR DEVELOPING STUDENT'S CREATIVITY IN SOCIOLOGY LESSON AT SMA N 6 YOGYAKARTA
}

\author{
RIRIN REVELATION PRIYANTI
}

\begin{abstract}
Researchers are interested in the creative learning strategies, then came the idea to apply them in the learning process in the classroom. So the local wisdom used to develop student creativity in the subject matter "of modernization and globalization".

This study included type of class action research. The formulation of the problem is: 1) whether the students' creativity can be increased with the applied method of utilizing local wisdom, 2) how the rest get to know the local culture and preserve it, 3) whether student performance can be further improved with the application of different learning methods on each cycle. The goal is to increase students' creativity, introduced directly to the assets of the local culture and improve student achievement.

In the first cycle, students are given the opportunity for group discussion in class, students are given a second cycle study method library and deducing the results in the form of articles, the third cycle students are assigned to visit while researching the existence of local cultural assets. The conclusion of this research: 1) increased student creativity, 2) student to know up close and be able to learn directly on aspects of local culture, 3) student achievement increased from cycle to cycle, the first cycle students $60 \%$ off, $75 \%$ the second cycle and the cycle three $100 \%$. The advice can be given, should be made in the model and the process of learning to develop creativity, preparation of teaching materials adapted to the characteristics and potential of the region, changes in methods of teaching sociology as a social science should be done by making use of local knowledge as a learning resource.
\end{abstract}

Keywords: local knowledge, creativity, learning strategies, socialization, "modernization and globalization" 


\section{Pendahuluan}

Motivasi menggali kearifan lokal sebagai isu penting dalam konteks menuju situasi sadar budaya, secara umum adalah untuk mencari dan akhirnya menetapkan identitas yang mungkin hilang karena proses budaya yang telah sedang dan akan terus terjadi sebagai sesuatu yang tak terelakkan. Dengan cara demikian, seluruh bangsa diharapkan memiliki kekenyalan budaya yang memadahi. Nilai-nilai kearifan lokal tersebut meniscayakan fungsi yang strategis bagi pembentukan karakter dan identitas yang pada gilirannya akan memunculkan sikap budaya yang mandiri, penuh inisiatif dan kreatif di era modernisasi dan globalisasi dewasa ini.

Pengembangan kearifan lokal yang relevan dan kontekstual memiliki arti penting bagi berkembangnya suatu masyarakat, terutama jika dilihat dari sudut pelestarian budaya, disamping mempunyai arti penting bagi identitas daerah yang bersangkutan akan mendorong rasa bangga akan budaya dan daerahnya. Dalam konteks di atas, pendidikan dapat diposisikan secara strategis. Artinya, pendidikan itu secara keseluruhan hendaknya dimaknai sebagai proses pembudayaan. Nilai tenggangrasa antar sesama dijadikan dasar utama di samping keanekaragaman keyakinan, adat dan tradisi ditempatkan sewajarnya dalam tegursapa yang ramah. Semua itu dapat terlaksana apabila materi dalam proses pendidikan dan pembelajaran memperhitungkan kearifan lokal.

Kreativitas memungkinkan manusia meningkatkan kualitas hidupnya. Dalam era pembangunan tidak dapat dipungkiri bahwa kesejahteraan dan kejayaan masyarakat dan negara ber- gantung pada sumbangan kreatif, berupa ide ide baru, penemuan penemuan baru, dan teknologi baru dari anggota masyarakatnya. Untuk mencapai hal itu, sikap dan perilaku kreatif perlu dipupuk dari sejak dini, agar peserta didik tidak hanya menjadi konsumen pengetahuan, tetapi mampu menghasilkan pengetahuan baru, tidak hanya menjadi pencari kerja, tetapi mampu menciptakan pekerjaan baru (wiraswasta).

Bagi guru, kemampuan kreatif merupakan aspek penting yang harus dimiliki untuk menciptakan lingkungan belajar yang mendorong peserta didik menjadi kreatif. Kemajuan dunia pendidikan memerlukan tingkat kemampuan kreatif yang tinggi dari para pendidik. Kreativitas peserta didik hanya bisa dikembangkan apabila gurunya kreatif. Guru yang kreatif memiliki kemampuan menyampaikan ilmu pengetahuan kepada para peserta didiknya secara kreatif, sehingga peserta didik menggemari ilmu pengetahuan yang diajarkan kepadanya dan membuat peserta didik dapat berpikir secara kreatif pula. Berpikir kreatif akan menghasilkan produk kreatif sehingga pada gilirannya akan menumbuhkan ekonomi kreatif bagi peserta didik.

\section{Rumusan Masalah}

1. Bagaimana kearifan lokal diimplementasikan dalam proses pembelajaran?

2. Bagaimana para siswa memiliki tingkat kreatifitas dalam proses pembelajaran?

3. Bagaimana agar para siswa memiliki rasa mencintai budaya lokal dan melestarikannya ditengah era modernisasi dan globalisasi?

4. Bagaimana agar prestasi belajar siswa meningkat? 


\section{Tujuan}

1. Agar kearifan lokal dapat diimplementasikan dalam proses pembelajaran

2. Para siswa memiliki kreatifitas dalam proses pembelajaran

3. Para siswa memiliki rasa mencintai budaya lokal dan melestarikannya di tengah era modernisasi dan globalisasi

4. Prestasi belajar siswa mengalami peningkatan'

\section{Pembahasan}

\section{Kearifan Lokal}

Pengertian kearifan lokal pada hakikatnya perwujudan dari pasal 38 (1) UU Sisdiknas yang menyatakan bahwa pelaksanaan kegiatan pendidikan dalam satuan pendidikan didasarkan atas kurikulum yang berlaku secara nasional dan kurikulum yang disesuaikan dengan kebutuhan lingkungan dan ciri khas satuan pendidikan. Sebagai tindak lanjutnya, muatan lokal telah dijadikan strategi pokok operasionalisasi link and match (Depdikbud, 1993), yakni memaksimalkan muatan lokal dan sejauh mungkin melibatkan peran serta masyarakat dalam perencanaan pelaksanaan program ini.

\section{Kreativitas}

Kreativitas sebagai faktor mental manusia telah lama diperbincangkan oleh para ahli, dan sejak tahun 1980-an Pusat Kurikulum Balitbang Depdiknas (dulu Pusat Pengembangan Kurikulum dan Sarana Pendidikan Balitbang Depdikbud) mulai berintensif membahasnya pada berbagai pertemuan ilmiah. Namun, sampia saat ini penerapannya di lapangan belum seperti yang diharapkan. Pendidikan di sekolah pada umumnya lebih menekankan pada pengembangan berpikir logis dan konvergen (berpikir ke satu arah) dengan melatih peserta didik untuk berpikir dan menemukan suatu pengetahuan yang sudah ditetapkan oleh guru. Kemampuan peserta didik untuk berpikir divergen (ke segala arah) dan memmecahkan masalah secara kreatif kurang diperhatikan dan kurang dikembangkan. Salah satu faktor penyebab yang sering dikemukakan oleh guru adalah terlalu saratnya beban belajar peserta didik dalam kurikulum (standar isi) sehingga guru merasa kekurangan waktu untuk mengembangkan kreativitas peserta didik.

\section{Strategi Pembelajaran}

Briggs (1977) menyatakan bahwa strategi pembelajaran selain untuk menentukan urutan pembelajaran setiap tujuan pembelajaran juga merancang tindakan-tindakan pembelajaran untuk mencapai tujuan pembelajaran tersebut. Strategi pembelajaran terdiri atas semua komponen materi pengajaran dan prosedur yang akan digunakan untuk membantu peserta didik dalam mencapai tujuan pembelajaran tertentu (Dick dan Carey, 1985). Dalam strategi pembelajaran sekurang-kurangnya terkandung 5 komponen utama, yaitu: 1) pengajaran, 2) penyampaian informasi, 3)peran serta siswa, 4)pengujian, 5) tindak lanjut (Dick dan Carey, 1985). Peran serta siswa yang paling besar pe ngaruhnya dalam proses pembelajaran adalah latihan. 


\section{Sosiologi}

Pada dasarnya sosiologi mempunyai dua pengertian, yaitu sebagai ilmu dan metode. Sebagai ilmu, merupakan kumpulan pengetahuan tentang masyarakat dan kebudayaan yang disusun secara sistematis berdasarkan analisis yang logis. Sebagai metode adalah cara berpikir untuk mengungkap realitas sosial budaya dengan prosedur dan teori yang dapat dipertanggungjawabkan. Tujuan pengajaran mencakup kognitif dan praktis. Secara kognitif, agar siswa mampu memahami dan menelaah secara rasional komponenkomponen dari individu, kebudayaan dan masyarakat. Secara praktis,untuk mengembangkan ketrampilan sikap dan perilaku siswa secara rasional dan kritis dalam menghadapi kemajemukan masyarakat, budaya dan berbagai masalah dalam kehidupan sehari-hari (Depdiknas, 2003: 8).

\section{Modernisasi dan Globalisasi}

Pengertian modernisasi adalah suatu proses menuju masa kini atau proses menuju masyarakat modern. Pengertian modernisasi menurut Wibert E. Moore adalah suatu transformasi total kehidupan bersama dalam bidang teknologi dan organisasi sosial dari yang tradisional ke arah pola ekonomis dan politis yang didahului oleh negara-negara barat yang stabil. Pengertian Globalisasi adalah sebuah istilah yang memiliki hubungan dengan pengalaman keterkaitan antarbangasa adan anatarmanusia, di seluruh dunia melalui perdagangan, investasi, perjalanan, budaya, popular dan bentuk-bentuk interaksi lainnya.

\section{Metode Penelitian}

Penelitian dilaksanakan pada semester genap tahun pelajaran $2011 / 2012$. Subjek penelitian kelas $X 5$ SMA Negeri 6 Yogyakarta dengan alamat di Jl. C.Simanjuntak No 2 Yogyakarta. Jumlah siswa 31 orang, dengan rincian 20 putri dan 11 putra. Satu kelas dibagi menjadi 5 kelompok.masingmasing kelompok 6 orang anggota dan ada satu kelompok yang anggotanya 7 orang. Populasi dan sampel sejumlah 31 siswa. Penelitian ini termasuk jenis class action research.

Tehnik dan alat yang digunakan adalah: 1) Lembar observasi, meliputi; a) aspek kreativitas; b) aspek prestasi. Aspek kreativitas meliputi; keaktifan siswa, keberanian mengungkapkan pendapat dalam diskusi, kesantunan dalam sikap dan penggunaan bahasa ketika diskusi. 2) penugasan, meliputi; a) Aspek mengenal dan melestarikan budaya lokal, meliputi; relevansi judul makalah dengan tema, orisinalitas karya, sistematika penulisan karya ilmiah, relevansi judul dengan isi makalah. Aspek prestasi dilihat dari persentase siswa dari siklus I sampai siklus III, melaui penilaian pada lembar observasi dan penugasan.

\section{Hasil dan Pembahasan}

Siklus I, guru menyiapkan kelas menjadi 5 kelompok (masing-masing 6 orang dan 1 kelompok beranggota 7 orang), tugas pada siklus I adalah diskusi kelompok di dalam kelas, dengan menggunkan media seadanya, yaitu buku diktat dan modul yang dimiliki siswa. Guru melakukan obsevasi untuk menilai 2 aspek pada lembar observasi yang telah disiapkan. Hasil observasi pada siklus I, sebagai berikut; 
Tabel I. Aspek Kreativitas Siswa dalam Kelompok

\begin{tabular}{|c|c|c|c|c|c|c|}
\hline \multirow[b]{2}{*}{ No } & \multirow[b]{2}{*}{ Indikator } & \multicolumn{5}{|c|}{ Jumlah siswa (\%) } \\
\hline & & $\begin{array}{c}\text { Kell } \\
\text { (6siswa) }\end{array}$ & $\begin{array}{c}\text { KellI } \\
\text { (6siswa) }\end{array}$ & $\begin{array}{l}\text { Kellill } \\
\text { (6siswa) }\end{array}$ & $\begin{array}{l}\text { KelIV } \\
\text { (6siswa) }\end{array}$ & $\begin{array}{c}\text { Kelv } \\
(7 \text { siswa) }\end{array}$ \\
\hline 1 & Keaktifan siswa & $\begin{array}{l}4 \text { siswa } \\
(66,7 \%)\end{array}$ & $\begin{array}{l}3 \text { siswa } \\
(50 \%)\end{array}$ & $\begin{array}{l}4 \text { siswa } \\
(66,7 \%)\end{array}$ & $\begin{array}{l}3 \text { siswa } \\
(50 \%)\end{array}$ & $\begin{array}{l}4 \text { siswa } \\
(57,1 \%) \\
\end{array}$ \\
\hline 2 & $\begin{array}{l}\text { Keberanian mengung- } \\
\text { kapkan pendapat }\end{array}$ & $\begin{array}{l}3 \text { siswa } \\
(50 \%)\end{array}$ & $\begin{array}{l}4 \text { siswa } \\
(66.7 \%)\end{array}$ & $\begin{array}{l}3 \text { siswa } \\
(50 \%)\end{array}$ & $\begin{array}{l}4 \text { siswa } \\
(66.7 \%)\end{array}$ & $\begin{array}{l}4 \text { tiswa } \\
(57,1 \%)\end{array}$ \\
\hline 3 & $\begin{array}{l}\text { Kesantunan dalam sikap } \\
\text { dan pengqunaan bahasa }\end{array}$ & $\begin{array}{l}4 \text { siswa } \\
(66.7 \%) \\
\end{array}$ & $\begin{array}{l}4 \text { siswa } \\
(66.7 \%)\end{array}$ & $\begin{array}{l}4 \text { siswa } \\
(66.7 \%)\end{array}$ & $\begin{array}{l}4 \text { siswa } \\
(66.7 \%) \\
\end{array}$ & $\begin{array}{l}4 \text { siswa } \\
(57,1 \%) \\
\end{array}$ \\
\hline & Rata-rata (\%) & $61,1 \%$ & $61.1 \%$ & $61.1 \%$ & $61.1 \%$ & $57.1 \%$ \\
\hline
\end{tabular}

Dari data observasi pada siklus I, rerata prestasi siswa untuk satu kelas dihitung; rata-ratanya sebesar $=61.1 \%$ $+61.1 \%+61.1 \%+61.1 \%+57.1 \%=$ $301.5 \%: 5=60.3 \%$.

Untuk itu guru melakukan refleksi, bagaimana pada pertemuan selanjutnya agar keterlibatan siswa dalam proses pembelajaran lebih optimal, harus diberikan metode penugasan yang berbeda.

Siklus II, diberikan kesempatan mengunjungi perpustakaan sekolah, tiap kelompok dibebaskan mencari sumber referensi dari pustaka dan media massa yang tersedia di perpustakaan yang ada kaitannya dengan tema; yaitu mengangkat kearifan lokal ditengah era modernisasi dan globalisasi. Hasil penelaahan pustaka dike- mas dalam bentuk artikel dan diserahkan pada guru untuk dinilai. Dari 31 siswa yang tersebut pada saat berada di perpustakaan , guru mengamati sikap siswa yang benar-benar serius diskusi mencari bahan untuk makalahnya atau yang Cuma ngobrol santai dan BBM-an dengan teman lainnya, diamati dan dihitung ada sekitar 8 siswa yang kurang aktif dan terlibat penuh dalam diskusi tersebut. Sedangkan yang lainnya serius membahas bahan untuk penyusunan makalahnya. Jadi pada siklus II, dicatat dalam lembar observasi ada sekitar 23 siswa yang aktif terlibat proses studylibrary atau sebesar $75 \%$.

Berikut hasil penilaian makalah yang dilakukan oleh guru:

Tabel 2. Aspek Mengenal dan Melestarikan Budaya Lokal

\begin{tabular}{|c|c|c|c|c|c|c|}
\hline No & Indikator & \multirow{2}{*}{\multicolumn{5}{|c|}{ (NilaikKM 72) }} \\
\hline & & Kell & & & KellV & Kelv \\
\hline 1 & Relevansi judul dengan tema & 75 & 80 & 75 & 75 & 75 \\
\hline 2 & Relevansi judul dengan isi makalah & 75 & 75 & 70 & 75 & 75 \\
\hline 3 & Orisinalitas karya & 75 & 75 & 75 & 75 & 75 \\
\hline 4 & Sistematika penulisan makalah & 75 & 80 & 75 & 75 & 75 \\
\hline & Rerata & 75 & 77.5 & 73.75 & 75 & 75 \\
\hline
\end{tabular}

Untuk itu guru melakukan refleksi, agar keterlibatan siswa dalam proses pembelajaran dapat mencapai $100 \%$, pada pertemuan selanjutnya akan diberikan bentuk penugasan yang lain.
Siklus III diadakan, setelah pertemuan minggu berikutnya untuk mengadakan ulangan harian materi sebelumnya yaitu"Sosialisasi dan Pembentukan Kepribadian". Sekaligus 
mengumpulkan makalah dari tugas minggu sebelumnya (studylibrary). Sehingga ada waktu 2 minggu hingga dikumpulkannya makalah hasil peneli- tian lapangan dan mempresentasikan di kelas. Berikut tabel hasil penilaian guru terhadap hasil karya kelompok:

Tabel 3. Aspek Mengenal dan Melestarikan Budaya Lokal

\begin{tabular}{|l|l|l|l|l|l|l|}
\hline \multirow{2}{*}{ No } & \multirow{2}{*}{ Indikator } & \multicolumn{5}{|c|}{ KilaikKM72) } \\
\cline { 3 - 7 } & Kell & \multicolumn{2}{|c|}{ Kell } & Kelll & Kell & KelV \\
\hline 1 & Relevansi judul dengan tema & 75 & 80 & 75 & 75 & 75 \\
\hline 2 & Relevansi judul dengan isi makalah & 75 & 80 & 75 & 75 & 80 \\
\hline 3 & Orisinalitas karya & 75 & 75 & 75 & 75 & 75 \\
\hline 4 & Sistematika penulisan makalah & 80 & 80 & 75 & 75 & 75 \\
\hline 5 & Presentasi & 75 & 80 & 80 & 75 & 80 \\
\hline 6 & Ketangkasan dalam menjawab pertanyaan & 75 & 80 & 75 & 80 & 80 \\
\hline & Rerata & 75.83 & 79.1 & 75.83 & 75.83 & 77.5 \\
\hline
\end{tabular}

Dari hasil wawancara dengan masing-masing kelompok, guru menyimpulkan bahwa semua anggota kelompok terlibat dalam proses penyusunan makalah penelitian dari tahap awal hingga akhir. Selain itu guru mengamati selama proses pembelajaran berlangsung seluruh siswa terlibat aktif, mereka memperhatikan ketika kelompok lain presentasi dan mengajukan pertanyaan-pertanyaan. Guru mengamati tidak ada siswa yang asyik ngobrol dengan temannya atau BBMan seperti yang dijumpai ketika pada siklus II. Sehingga menurut penilaian guru, sejumlah 31 siswa atau sebesar $100 \%$ terlibat aktif dalam proses pembelajaran pada siklus III ini.

\section{Kesimpulan}

Berdasarkan uraian di atas dapat disimpulkan hal-hal sebagai berikut:

1) Kearifan lokal yang ada di daerah kita dapat diimplementasikan dalam proses pembelajaran

2) Siswa dapat mengembangkan kreativitasnya dalam proses pembelajaran dengan diberikan waktu untuk mencari dan menggali sendiri pemahaman dan ilmu dari sumber lain selain gurunya

3) Siswa dapata tumbuh rasa memiliki, mencintai budaya lokal dan ingin melestarikannya meskipun mereka lahir pada era digital dan dikepung dengan modernisasi dan globalisasi

4) Prestasi belajar siswa meningkat dari siklus I, sebesar $60 \%$ menjadi $75 \%$ pada siklus II dan menjadi $100 \%$ pada siklus III

\section{Daftar Pustaka}

Cony Semiawan,dkk.(1985). Pendekotan ketrampilan proses: bogaimana mengaktikkan siswa dalam belajar? Jakarta: Gramedia.

Hamzah B.Uno. (2007). Model pembelajaran: menetapkan proses belojor mengajar yang kreatif dan efektif. Jakarta: Bumi Aksara.

Kun Maryati. (2010). Sosiologi 3 untuk SMA dan MA kelos XII. Jakarta: ESIS.

Suminto A.Sayuti.(2011). Pengembangan dan pemanfaatan kearifan lokal dalam proses pendidikan. Yogyakarta: Makolah Seminar.

Tim Sosiologi. (2010). Sosiologi kelas x. Jakarta: Yudhistird. 